\title{
Using Value Models to Improve the Cost/Benefit Analysis of Inter-Organizational System Implementations
}

\author{
Silja Mareike Eckartz ${ }^{*}$, Christiaan Katsma, and Roel Wieringa \\ University of Twente, The Netherlands
}

\begin{abstract}
Jointly developing a business case for inter-organizational information systems (IOS) is difficult as: (1) in a business network there are benefits that may not appear at the site where costs occur, and (2) the involved stakeholders often have different or even conflicting organizational goals. This paper analyzes the use of value modeling as a way to address these two challenges and support business case development in a network. We carried out a case study to explore the usefulness of the value modeling logic during an IOS implementation project and conclude that the integration of value modeling into business case development can help to improve the quality of the business case. The value model allows business partners to get insights into the way value is exchanged in the network and check the distribution of costs and benefits, yet doing so without having to reveal confidential details about internal business processes.
\end{abstract}

Keywords: Value modeling, Business case development, Inter-organizational system implementation.

\section{Introduction}

Decision makers in the current practice of IS implementations develop or receive a business case in which costs, benefits and risks of the project are estimated [1]. However, current business case development methods are expected to be of limited applicability in inter-organizational projects due to their complex nature. Cash and Konsynski [2] define an inter-organizational information system (IOS) as "an automated information system shared by two or more companies". It enables joint service delivery to customers and coordination between profit-and-loss responsible business units, or between independent companies [3]. We refer to these as stakeholders in the remainder of this paper.

One of the main challenges in IOS implementations is to address different or even conflicting organizational goals of the involved stakeholders. In the case that some or all business goals are conflicting, the partners in this cooperation are not likely to reveal sensitive information [4]. A second challenge is that the costs do not occur at the same point in the network where the benefits of the implementation are gained.

\footnotetext{
* This research project was part of the NWO VITAL project (Project nr. 638.003.407).
} 
This paper analyzes the use of value modeling as a way to address these challenges and support business case development between different stakeholders in a network. We follow a design science approach and extend current value modeling logic to the domain of inter-organizational business case development. Business case development is already supported by a variety of tools and methods. Therefore, our research objective is a focused contribution to the value definition and knowledge sharing on the value distribution in an inter-organizational setting. We do so by developing a method called value modeling for inter-organizational projects (VM4IOP). In this paper we will specify the typical challenges for interorganizational business case development in the background section $\$ 2$ and proceed by illustrating the deployment of the VM4IOP method, using the example of a case study at the harbor of Rotterdam in $\S 4$. Our design science research approach is explained in $\$ 3$.

\section{Background}

The implementation of IOS to support inter-organizational coordination is essentially a joint effort: Stakeholders first jointly need to agree on the prospective (business) goals, and then investigate and implement the information system solutions that fit these objectives. In the beginning stages of such an implementation this is supported by the development of a business case.

'Business case' is an ambiguous term often used by practitioners to refer to the relatively simple cost-benefit calculation being done for many management decisions. The business case describes and guides the evaluation of different implementation options, based on the expected costs, benefits and risks of each option. It is often used to support top management in deciding into which projects they want to invest, and it also is the highest-level requirements specification of a project. The business case is often accompanied with net present value, total cost of ownership or similar methods to support and specify cost benefit calculations.

In an inter-organizational IS implementation, the traditional business case approach does not make clear which partners get which part of the benefits and which partners incur which part of the costs, and if the costs and benefits balance per partner. Often, in a network, benefits accrued by one partner depend on costs incurred by another. These differences in the distribution of cost versus benefits may not even be the critical element, but the involved stakeholders require that costs and benefits would be distributed fairly across the business network during and after this implementation. This opens up the discussion between stakeholders on the fairness distribution. With fair we refer to a situation where (i) the stakeholders that has the most value from the IS implementation also pays the largest share of the cost and (ii) all individual stakeholders are profitable as well as the entire network. The perception of an unequal cost-benefit distribution among partners can lead to mistrust and in some situations might even then end the implementation effort.

We analyzed the combination of value models and business case development to address the problem of investment decision-making in a network. Value models can 
assist to explicate how value is exchanged within each organization, but also between the actors in a network of separate organizations.

A value model contains a set of objects, concepts and their relationships with the objective to express the business logic of a specific firm [5,6]. It provides powerful ways to understand, analyze, communicate, and manage strategic-oriented choices among business and technology stakeholders [6]. The origins of value models stem from the business modeling literature [7] specifying e-commerce applications. The current value modeling literature provides several methods, such as e3value [8], that are specifically designed for network settings [9].

Combining the challenges of inter-organizational business case development and the contributions of value modeling we conclude a value model allows business partners to:

(i) get insights into the way value is exchanged both within the organization as well as in the current network [10];

(ii) compare and assess the impact of different solutions on the business situation of each individual stakeholder as well as the entire network;

(iii) discuss and check that a business idea will be implemented fairly, i.e. balancing costs and benefits, share the mutual perceptions between the stakeholders yet doing so without having to reveal confidential details about internal IT investments or business processes.

We acknowledge the existing business case methods and tools [11,12] and also the contributions from the domain of decision support, trust and the negotiation process $[13,14]$, but we see an opportunity for value modeling as method to contribute to networked business case development. We expect that the use of value models in the beginning of an IS implementation project helps the stakeholders to get better insights into their network. Open communication helps to initiate the group discussion by disclosing information step by step [15], which in turn increases the development of trust between the stakeholders of a project.

\section{Research Method}

Using design science [16] we developed a method (VM4IOP) that addresses some of the problems, identified in earlier research, concerning the development of a business case in inter-organizational projects [17]. Using an iterative design setup we discussed the method with several experts and academics. The method was deployed during a case study at the port of Rotterdam in The Netherlands. We will use this case as an example in this paper. However, we make the note that the value models presented in this paper were only discussed with the members of the research project and not yet with all practitioners normally involved in such a project.

The case study at the port of Rotterdam involves multiple actors in a network that are engaged in the process of making a joint decision on an IT investment. More specifically, barge operators, terminal operators and the harbor authority discussed how a multi-agent system could support logistic planning in the port of Rotterdam. 
Our case study was part of a bigger research effort: Transumo (www.transumo.nl), a platform where 150 parties from industry, government and academia jointly develop knowledge about sustainable mobility. We were involved in a business case work package of a larger project [18] that aimed at the design and implementation of a multi-agent system for the port of Rotterdam. Our role in this case study was inquisitive as well as advisory. In total, three researchers were involved alternately during our 7-month long participation in the case study. All researchers were familiar with business case approaches; two of them had practical experience in applying them in real life settings. We took both expert-based as well as participant-observationbased approaches and conducted various unstructured qualitative interviews to gather information about the business case development process. While collecting and analyzing the observations and the interviews, we focused on findings related to the business case development process as well as its outcomes. In our design effort specifically aimed to validate the value models we involved 5 researchers. We thus did not validate the models with all practitioners involved in the project, but based on the findings of Pijpers et al. [19], we expect business professionals will not be confronted with substantial impediments to work with these models.

Figure 1 presents the relations between the actors in our case setting. The figure represents both the contract relations between the actors as well as the container flow in the network. One can see that containers are transported from the line shipper via several terminal barge and truck operators to the merchant and vice versa. Barges are used to transport containers from the harbor, in our case study the port of Rotterdam to the hinterland and vice versa. Whenever a barge visits the port, it has to call on several terminals to load and unload containers. To guarantee short sojourn times in the port, the barge operator schedules convenient arrival times at the concerning terminals. The terminal operators want to operate efficiently and have to decide when a barge can be processed, taking into account all kinds of restrictions, e.g. specific times at which containers need to be at the terminal. For our project the actors jointly needed to come to an agreement about their shared business case.

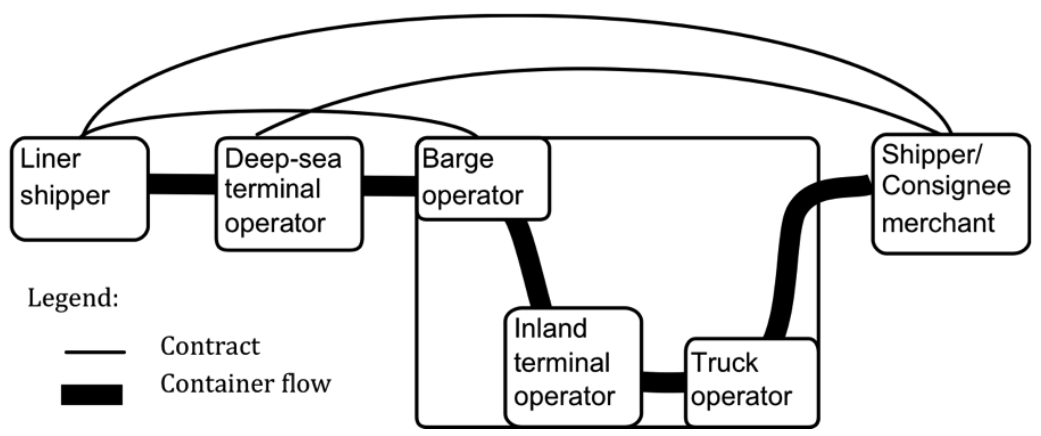

Fig. 1. Contract model, harbor case study setting 


\section{The VM4IOP Method}

The VM4IOP method uses value models as main tool to provide insights into the network structure in an inter-organizational project. It does so by:

- Explicating the relations between stakeholders in a network.

- Providing a structured approach that helps to specify the value distribution in a network. This structured approach fits the dynamics of the business case development process.

The method treats the business case development process as project in the beginning of the entire IS implementation project. The deployment process consists out of the following three main steps. Some of the steps require individual activities of all involved stakeholder others are a group effort.

- Step 1: Assess the entire network with the help of a value model to recognize that there is a problem (group effort).

- Step 2: Assess the value model of each individual actor to investigate the problem in more detail.

o Step 3: Assessment of solution options. For each solution option clarify the changes in the network when a certain solution is implemented with the help of the value model (group effort).

We will now describe each of the three deployment steps in more detail and give an illustration for its deployment using the harbor case.

\subsection{Step 1: Assessment of the Current Network Constellation}

Before the start of the business case development project the VM4IOP method is deployed to assess the profitability of the entire network. This activity results in a value model of the entire network, showing from a holistic point of view how the different actors are interacting with each other and how value is exchanged. Value models help the stakeholders to share their understanding regarding the collaboration and enable them to analyze the economic sustainability of the network. The main goal of value modeling is to reach agreement amongst profit-and-loss responsible units in a network regarding the question "Who is offering what value to whom and expects what value in return?" Once it is understood how different actors exchange value in a network, problems in the current network situation can be identified and located. Value objects can be money, products, services, or even experiences. Especially this aspect is important as it offers the involved practitioners a way to discuss the concept of value, explain it to each other and specify it [10].

Illustration: When we started our case study in the harbor there was no common understanding how the different actors currently create value in the network they are involved in. However, it was know how goods are flowing through the network and which actors have a contractual relation with each other. The contract model 
presented in Figure 1 was used as a basis for drawing the value model of the current network situation, shown in Figure 3.

The analysis of the models explicates where in the current network constellation a problem exists and why it might difficult to be solved. In this case we find that the shipper (upper left corner in Figure 3), as the customer of this network, has a need that can be fulfilled by executing two value streams of shipping service (the continuous lines). We also observe the value transactions are connected by the dashed lines, called dependency paths. The dependency path says nothing about the order in which these transactions must be performed. Rather, it expresses only the economic transactions that must be performed to satisfy a consumer need. We further find that all value exchanges happen via the shipper and the carrier. Although the container flow between barge operators and terminal operators describes the core of the network (Figure 1), there is no contractual relation or value exchange between these two important actors. As they might have conflicting goals they might tend to act selfish, as there is no contract with consequences specified.

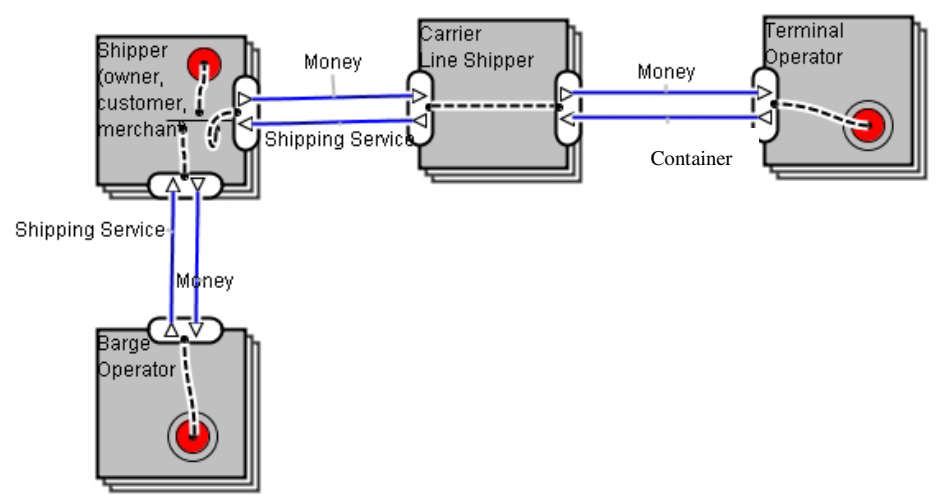

Fig. 2. Value model harbor network - current situation

\subsection{Step 2: Individual Assessment of Current Network Situation}

Once the problems with the current network constellation are identified and the project is started, each individual actor is encouraged to zoom in on the collaborative value model and, as extension to it, develop their own value model. This activity should happen in the problem investigation phase when the as-is business situation is analyzed in terms of organizational mission, vision and goals. In this phase each actor can analyze how he exchanges value with other actors in the network. Based on this analysis each actor should decide if a change in his current situation is needed and if this change incorporates better alignment, collaboration or information transfer with other actors in the network. The resulting "actor specific value model" (as shown in Figure 4) can be used to identify problems with current business situation and support the stakeholder to decide if he wants to continue to participate in the project at hand. 


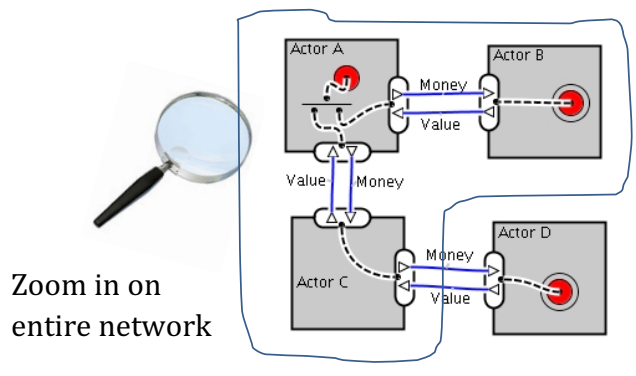

Fig. 3. Actor level value model of current situation

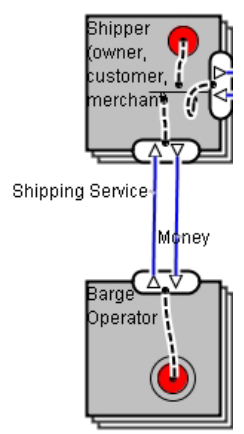

Fig. 4. Value model from the perspective of the barge operator in harbor case

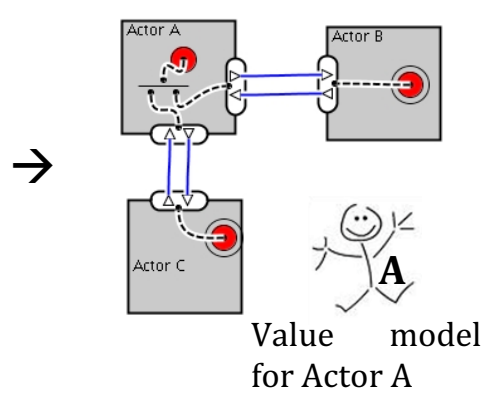

for Actor A

\begin{abstract}
Illustration: When zooming in on the network from the perspective of the barge operator, we arrive at the value model shown in Figure 5. This value model shows all actors that the barge operator has a transaction with, given the focus of the project. This figure shows us that in the current value network the barge operator exchanges value with the shipper, in terms of shipping service for money. Even though the barge operator and the terminal operator physically meet in the harbor no value exchange is depicted in their current value model. Not having a specified exchange of value makes the problem at hand very complex.
\end{abstract}

\subsection{Step 3: Assessment of Solution Options - Link Costs and Benefits to the Value Models}

Following the problem investigation, the next steps in the business case development process are executed: solution options are identified and assessed first by each stakeholder individually, afterwards collaboratively. Depending on the complexity of the implementation options, the actors might find it useful to construct a value model for each solution option that can be used as input to clarify the business case. The value model allows the actors to specify for each solution option how their network changes once a solution is implemented e.g. it might be that the actors with which an actor does business change and that new actors enter the network.

With respect to the linkage between the business case and the value model we require that all costs listed in the business case be translated into cash outflows, be it expenses or one-time investments. Cash outflows are represented as value exchanges in the e3value-modeling notation and can further be specified in the properties of actors (expenses and one time investments) or value ports (only expenses). 


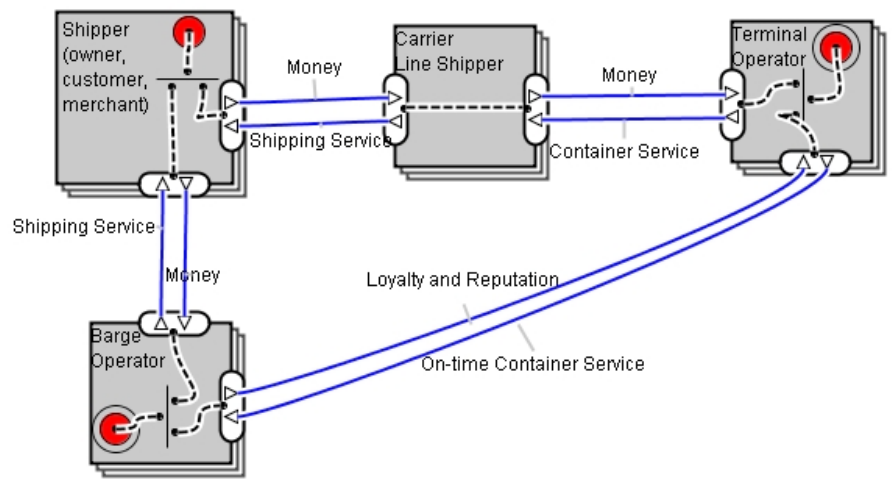

Fig. 5. Value model solution option 1 for the harbor case

Inclusion of the benefits in the value model seems to be more difficult. Financial benefits can be shown as cash inflows related to a particular value exchange. Adding all financial benefits as value exchanges in the value model may result in a very complex value model. The idea of value modeling (in the e3value sense) is to translate everything into financial numbers based on which the profitability analysis can be run. Thus, including intangible benefits as value streams (e.g. loyalty, reputation) in the value model is only useful when a financial value can be assigned to it. This is often a challenging task which is based on many assumptions as some of the benefits can only be expressed through indirect effects e.g. on the overall profitability. However, it is the only way that benefits can be made visible at a network level [10].

Illustration: Two example value models from our harbor case are shown in Figure 6 and Figure 7. The first value model introduces a solution that is based on a "loyalty and reputation in return for on-time container service" relation between the barge and terminal operators. Compared with the original value model, this is the only change; no new actors enter the network.

The second value model specifies a solution where an IOS (in this case called PAT) is implemented that is operated by a 3rd party. Figure 7 shows how the network constellation and value exchanges in the network change, e.g. by adding a new actor to the network. Other solution options one can think of can be assessed using the value models in a similar way.

The developed value models provide useful insights for each individual actor, but also for the entire network that can be used during the cost distribution and agreement making process. This process can be supported by the use of discussion support systems or negotiation interventions, but the value models deliver a valuable input to support these methods with knowledge and content. Knowing how value is currently distributed in the network and how the different implementation options change this value distribution serves as a solid basis for discussing which actor pays what part of the total investment costs. 


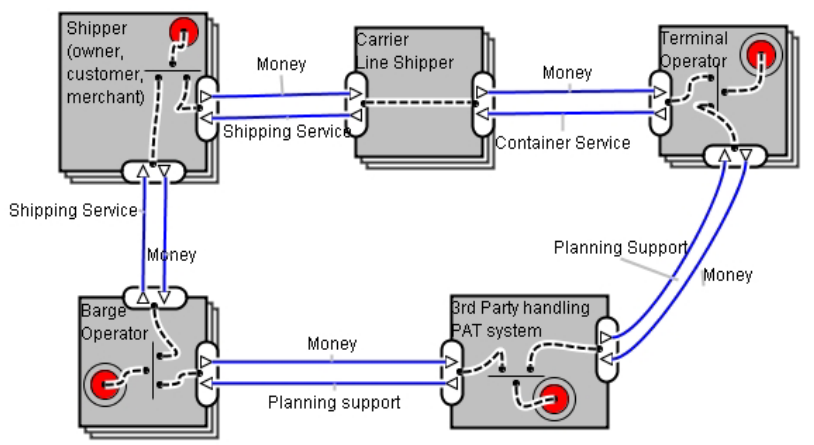

Fig. 6. Value model solution option 2 for the harbor case

\section{Conclusions}

Networked businesses have been leading to an increase in inter-organizational IS implementations. These implementations include some specific challenges that not always are completely supported by existing business case development approaches. Value modeling itself has been maturing and lately we have seen the first results from its application in inter-organizational settings. In this paper we have shown the results from an iterative design study in an extensive research project with scientists and practitioners. We apply value models in an inter-organizational business case development context. Our results show our VM4IOP method especially contributes to challenges often encountered in making the business case in an inter-organizational project. First, it specifies value streams -and mechanisms between the different actors and by doing so shows the involved actors the differences between cost and benefits and their location in the network. This is possible without having to reveal confidential details about internal IT investments or business processes for individual actors. Secondly, VM4IOP initiates and facilitates the group discussion and knowledge sharing in a setting where participants have conflicting goals by differentiating between private and public value streams and information.

Value modeling by no means is the only necessary improvement of business case development in inter-organizational settings. The addition of a value model to a business case improves the quality of the business case because the various options relevant to the network's actors are presented explicitly and, in turn, are understood better. Value exchanges are well reasoned about regarding the level of fairness they imply for the distribution of the costs and benefits among stakeholders in an IOS project. But our illustration also indicates the complexity of IOS implementations requires more than the mere addition of one specific modeling approach, like value modeling. We have strong indications that the addition of interventions or tools to support negotiation and discussion as well as decision support methods dedicated for the inter-organizational situation can be helpful. We recommend further research in that domain. Our results also show professionals are able to deploy the VM4IOP 
method in an applied research project. Another next logical step is to validate and analyze the VM4IOP method in a commercial real life project and specify the requirements for negotiation support in IOS projects.

\section{References}

[1] Remenyi, D.: IT Investment: Making a Business Case. Butterworth-Heinemann, Oxford (1999)

[2] Cash Jr., J.I., Konsynski, B.R.: IS redraws competitive boundaries. Harvard Business Review 63(2), 134-142 (1985)

[3] Bakos, J.: A strategic analysis of electronic marketplaces. MIS Quarterly, 295-310 (1991)

[4] Daneva, M., Wieringa, R.J.: A Requirements Engineering Framework for Crossorganizational ERP systems. Requirements Engineering 11(3), 194-204 (2006)

[5] Magretta, J.: Why business models matter. Harvard Business Review 80(5), 86-92 (2002)

[6] Osterwalder, A., Pigneur, Y., Tucci, C.L.: Clarifying Business Models: Origins, Present, and Future of the Concept. Communications of AIS 15 (2005)

[7] Timmers, P.: Business models for electronic markets. Journal on Electronic Markets 8(2), 3-8 (1998)

[8] Gordijn, J.: Value-Based Requirements Engineering: Exploring Innovatie E-commerce Ideas. Vrije Universiteit Amsterdam, Amsterdam (2002)

[9] Osterwalder, A., Pigneur, Y.: An e-Business Model Ontology for Modelling e-Business. In: Proceedings of 15th Bled Electronic Commerce Conference - e-Reality: Constructing the e-Economy, Bled, Slowenien (2002)

[10] Ilayperuma, T., Zdravkovic, J.: Exploring business value models from the interorganizational collaboration perspective. In: Proceedings of the 2010 ACM Symposium on Applied Computing (SAC 2010). ACM, New York (2010)

[11] Ward, J., Daniel, E., Peppard, J.: Building Better Business Cases for IT Investments. MIS Quarterly Executive 7(1), 1-15 (2008)

[12] Ross, J.W., Beath, C.M.: Beyond the Business Case: New Approaches to IT Investment. MIT Sloan Management Review 43(2), 51-59 (2002)

[13] DeSanctis, G., Poole, M.S., Zigurs, I.: The Minnesota GDSS Research Project: Group Support Systems, Group Processes, and Outcomes. Journal of the Association for Information Systems 9(10), 551-608 (2008)

[14] Edelenbos, J., Klijn, E.-H.: Trust in Complex Decision-Making Networks: A Theoretical and Empirical Exploration. Administration \& Society 39, 25-50 (2007)

[15] Camarinha-Matos, L.M., Macedo, P.: A conceptual model of value systems in collaborative networks. Journal of Intelligent Manufacturing 21(3), 287-299 (2008)

[16] Wieringa, R.J.: Design Science as Nested Problem Solving. In: International Conference on Design Science Research in Information Systems and Technology (DESRIST). ACM, Malvern (2009)

[17] Eckartz, S., Katsma, C., Daneva, M.: Exploring the Business Case Development Process in Inter-Organizational Enterprise System Implementations. Information Resources Management Journal (IRMJ) 25(2), 85-102 (2012)

[18] Douma, A., Schuur, P., Jagerman, R.: Degrees of terminal cooperativeness and the efficiency of the barge handling process. Expert Systems with Applications 38, 35803589 (2010)

[19] Pijpers, V., de Leenheer, P., Gordijn, J., Akkermans, H.: Using conceptual models to explore business-ICT alignment in networked value constellations. Requirements Engineering, 1-24 (2010) 